\title{
The International Teaching and Practice of Cryobiology and Biobankology Course in China
}

\author{
Hongkang Zhou, Xiuyu Wu,, Leping Zeng,, Xiaoxin Yan, Wei Tian,, Kun Xiong,, and Jufang Huang ${ }^{1}$
}

In the past 10 years, clinical biobanks have experienced increasing expansion in China. Demand for systematically educated biobanking professionals is a priority for Chinese biobanks' agenda. The cryobiology and biobankology course is the first semester-long course in China, designed and developed at Central South University with international cooperation. Leading professors were from China, the United States, United Kingdom, and Canada to teach the latest version of biobanking knowledge and skills around the globe. This course is a comprehensive elective course with six specific teaching modules, which is suitable for graduate students majoring in basic medical sciences, clinical medicine, life sciences, mechanical engineering, and biomedical engineering, who would like to seek biobanking careers in the future. Participants from China, Czech Republic, Ghana, Madagascar, Tanzania, South Sudan, and Israel attended the course. Through taking this course, students can broaden their international academic horizons and cultivate the ability to learn and apply the knowledge of biology, medicine, and engineering to analyze and explain the low-temperature biology and clinical samples-based research practice. At the same time, the course enables students to realize the importance of multidisciplinary fields of biobanking and the significance of innovative precision medicine research, and further enlightens students' enthusiasm to pursue biobanking professional careers, and in the future they can proudly call themselves "biobankers."

Keywords: biobanking education, cryobiology, biobankology, multidisciplinary, graduates, social media

\section{Background}

$\mathrm{O}$ WING TO THE complex characteristics of biobanking, training and education of biobanking professionals require related expertise from many fields, including medicine, engineering, quality management, ethics, laws and regulations (national and international), logistics, informatics, and business management. ${ }^{1-3}$

In recent years, multiple biobanking courses and educational programs have been developed and provided in many countries. $^{4,5}$ Since 2010, some European countries (France in 2010, Spain in 2011, United Kingdom in 2015, and Austria in 2016) have established full-time 1-2 years master degree programs in biobanking, which present the most complete educational courses in parallel with hands-on training in various biobanks. Besides Europe, short courses in biobanking (both online and on-site) have been formulated by universities and biobanks in Arab countries, ${ }^{6}$ Australia, Canada, ${ }^{5}$ and the United States. ${ }^{4}$ These courses provide lectures, workshops, and tutorials varying from several days to weeks ${ }^{4,7}$ and most of them are taught by their own institutional faculty members and biobanking experts. However, so far, there is no single course of these types offered in China.

Alongside the expansion of translational and precision medicine research in China, ${ }^{8}>49$ large biobanks have been established in the past 10 years with an estimated 100,000 biospecimens stored in each and several hundred mediumsize biobanks are also now distributed across China ${ }^{9-11}$ In 2017, a national-level survey of the current situation of biobanks in China demonstrated that $73.8 \%$ of the biobanks have insufficient numbers of employees and that almost $50 \%$ of the biobanks stated that their staff need more professional training. ${ }^{12}$ The demand of more properly trained biobanking staff and personnel is, therefore, also urgent for biobanks in China.

In 2018, Central South University (CSU) in Changsha China established the first comprehensive biobanking course available in China, entitled Cryobiology and Biobankology. This course was organized and taught by international collaboration with leading experts from the International Society for Biological and Environmental Repositories (ISBER) and

Departments of ${ }^{1}$ Anatomy and Neurobiology and ${ }^{2}$ Immunology, School of Basic Medical Sciences, Central South University, Changsha, China. 
the most experienced biobanking professors at top Chinese universities and research institutes.

\section{Methods: Learner and Curriculum Focus}

The Cryobiology and Biobankology (course number 65100111216) is a graduate-level course provided at the CSU School of Basic Medical Sciences. The course was developed and first launched in 2018. The official language used for teaching is English. It involves coursework for 2 days/week for an 8-week period. This targeted course audience is graduate students who are interested in knowing about biobanking research and seeking future biobanking careers. This is a campus-wide major elective course with open registration for all graduate students at the University.

The Cryobiology and Biobankology course was jointly developed by 10 professors and representatives from CSU, Tsinghua University, the Chinese Academy of Sciences Technical Institute of Physics and Chemistry, the University of Shanghai for Science and Technology, University of Minnesota, three leading experts from ISBER and the World Health Organization-International Agency for Research on Cancer (WHO-IARC), and Oasis Diagnostics ${ }^{\circledR}$ Corporation. This committee developed the curriculum of the biobanking course, to include 14 theoretical teaching classes ( 28 hours) and 2 practical training sessions (4 hours). The organization of the course is summarized in Table 1.

In the introduction to biobanking module, three related topics were created: (1) introduction to cryobiology and biobankology, (2) history of biobanking (based on case studies), and (3) introduction to biobanking in China.

The module of basic theories and technologies for biobanking included three topics; the basic theories of cryobiology and cryomedicine-freezing properties of aqueous solution and cell injury, and the basic theories of cryobiology and cryomedicine, and vitrification theory and its application, and cryosurgical techniques and applications.
Biobank construction and management are the cornerstones and keys to the success of biobanking activities. In this module, three topic areas covered biobanking networks, quality assurance and quality control programs, and safety in biobanking.

Around the world, legal and ethical issues of biobanking are major concerns of the public. In this class module ethical, legal, and social aspects that are commonly involved in or relevant to biobanking are covered.

In the applications of biobanks teaching module, three topics are presented. The first module is preservation for cellular therapies followed by outlining biobank and applications in various omics fields; and lastly, a focus on brain biobanking.

\section{Results: Participants, Marketing, and Feedback}

The overall cost of developing this course was $\sim 121,000$ Chinese Yuan ( $\sim \$ 17,000$ USD). There is no cost to enroll in the course for students who are already officially enrolled at the CSU. The course is offered annually, every fall semester.

A total of 45 graduate students participated in the first offering of the course in the Fall 2018. The characteristics of this cohort were as follows; equal male:female ratio, a majority of students were from the School of Basic Medical Sciences $(75.6 \%)$, with others from the schools of medicine (20\%) and life sciences (4\%), and the nationalities of the students spanned seven countries (Fig. 1). Similarly, the nationalities of the academic committee also spanned four countries (China, United States, United Kingdom, and Canada).

Evaluation of students mainly involved three components. First, during the many class breaks, attending students were divided into several groups (5-9 students/group) and asked to write down their answers to five class-related questions and to discuss with each other. The responses from this collaborative teamwork were presented to the whole group

Table 1. Teaching Modules and Topics of Cryobiology and Biobankology Course

\begin{tabular}{|c|c|c|c|}
\hline Modules & Topics & $\begin{array}{l}\text { Lecturel } \\
\text { practice }\end{array}$ & Duration \\
\hline \multirow{4}{*}{ Introduction to biobanking } & Introduction to cryobiology and biobankology & Lecture & 2 hours \\
\hline & History of biobanking (case study) & Lecture & 2 hours \\
\hline & Introduction of biobanking in China & Lecture & 2 hours \\
\hline & $\begin{array}{l}\text { The basic theories of cryobiology and cryomedicine (I)-freezing } \\
\text { properties of aqueous solution and cell injury }\end{array}$ & Lecture & 2 hours \\
\hline \multirow{2}{*}{$\begin{array}{l}\text { Basic theories and } \\
\text { technologies for } \\
\text { biobanking }\end{array}$} & $\begin{array}{l}\text { The basic theories of cryobiology and cryomedicine (II)- } \\
\text { vitrification theory and its application }\end{array}$ & Lecture & 2 hours \\
\hline & $\begin{array}{l}\text { Cryosurgical techniques and application } \\
\text { biobanking network }\end{array}$ & $\begin{array}{l}\text { Lecture } \\
\text { Lecture }\end{array}$ & $\begin{array}{l}2 \text { hours } \\
2 \text { hours }\end{array}$ \\
\hline $\begin{array}{l}\text { Legal and ethical issues } \\
\text { of biobanking }\end{array}$ & $\begin{array}{l}\text { Ethical, legal, and social aspects in biobanking } \\
\text { Preservation of cellular therapies }\end{array}$ & $\begin{array}{l}\text { Lecture } \\
\text { Lecture }\end{array}$ & 2 hours \\
\hline Applications of biobanks & $\begin{array}{l}\text { Type of biobanks and applications in various omics } \\
\text { Brain biobanking }\end{array}$ & $\begin{array}{l}\text { Lecture } \\
\text { Lecture }\end{array}$ & $\begin{array}{l}2 \text { hours } \\
2 \text { hours }\end{array}$ \\
\hline \multirow[t]{2}{*}{$\begin{array}{l}\text { On-site biobank practice } \\
\text { training }\end{array}$} & $\begin{array}{l}\text { Basic practice in biobanking (I)-urine sample collection } \\
\text { and related omics studies }\end{array}$ & Practice & 2 hours \\
\hline & $\begin{array}{l}\text { Basic practice in biobanking (II)-blood sample collection } \\
\text { and storage techniques }\end{array}$ & Practice & 2 hours \\
\hline 6 modules & 16 topics & $\begin{array}{l}14 \text { lectures } \\
2 \text { practices }\end{array}$ & 32 hours \\
\hline
\end{tabular}


and evaluated, but also individual students' work was recognized. This part of class recruited all students to join in the detailed discussion of biobanking questions, and at the same time debate the answers of the question inspired new ideas for biobanking. Second, in the two biobanking practice training sessions (4 hours), students were required to independently collect, transport, process, store, and preanalyze a specific type of biospecimen (blood or urine samples). This exercise was evaluated by a biobanking mentor. Finally, at the end of the biobanking course, students were asked to write an essay structured into three parts: a comprehensive description of the course content, the most significant new knowledge that students had learned from the course and a summary of what aspects of this course were most helpful and inspirational, and their comments and suggestions for this course. Students' course summaries were evaluated by international members of the academic committee. The average score was $87.3 \%$.

\section{Discussion and Future Directions}

This course provided graduate-level biobanking education for students who may be interested in devoting their careers to the management of biospecimen resources for research. There are significant shortages of qualified biobanking professionals with systemic education and training $^{14-16}$ and this has become an urgent need for development of biorepository infrastructures. One essential reason is that the lack of awareness of young sciences students. Biobanking is a relatively new concept in China. Therefore, attracting substantial numbers of students with life and medical sciences backgrounds to join the field of biobanking and training them as professional biobankers is a challenge.

As such, effective marketing of the Cryobiology and Biobankology is important. This course was mainly advertised through the official account of the Xiangya biobank (account name: HNebiobank) in the WeChat app. This app is similar to WhatsApp and Facebook but is more popular in China. The daily active $\mathrm{WeChat}$ users have reached one billion in $2019 .^{13}$ In China, almost every college student has his/her own personal WeChat accounts for daily social networking and interacting. "WeChat Articles" were composed for each topic of the course (16 articles in total) and posted 1 week ahead of the class launch date. The major targets for advertising were undergraduate and graduate medical/life sciences students at CSU and so the course advertising was written in a specific style for this group, while adding colorful cartoon pictures and animations to attract students' attention. During the course these articles received a cumulative 4025 reads and on average there were 252 reads for each topic. Meanwhile, there were 313 followers interested in the biobanking course and who had read through the articles and $45(14.3 \%)$ students among them participated in the classroom of the course.

Aside from the WeChat tweeting strategy, at the beginning of the 2018 fall semester, the Xiangya biobank initiated the "Clinical Biobanking Awareness Week." For this event, specific materials such as posters, banners, flyers, seminars, and workshops with biobanking course information had been developed and used to reach out to all three satellite campuses of the CSU. At the nationwide level, the course was also advertised to the Biobank Branch of China Medicinal Biotech Association (BBCMBA) conferences, the Annual Biobank China 2018 meeting, the eBiobank platform, which is run by the China National Gene Bank, and biobanking stakeholder companies.

To raise the profile of biobanking education and increase broad awareness of the life science community, in the future we plan to formulate an online biobanking course series based on this course in both Chinese and English, which could be available for low-income and limited resources regions/countries. This approach will enable distant learning and establish teaching resources for rural and limited resource regions and areas, making biobanking knowledge and skills more accessible. It is also important to make this course become an integral part of the education available to the international biobanking community. We will apply for course endorsements from ISBER and request to add our
FIG. 1. Chinese and international students' distribution by countries.

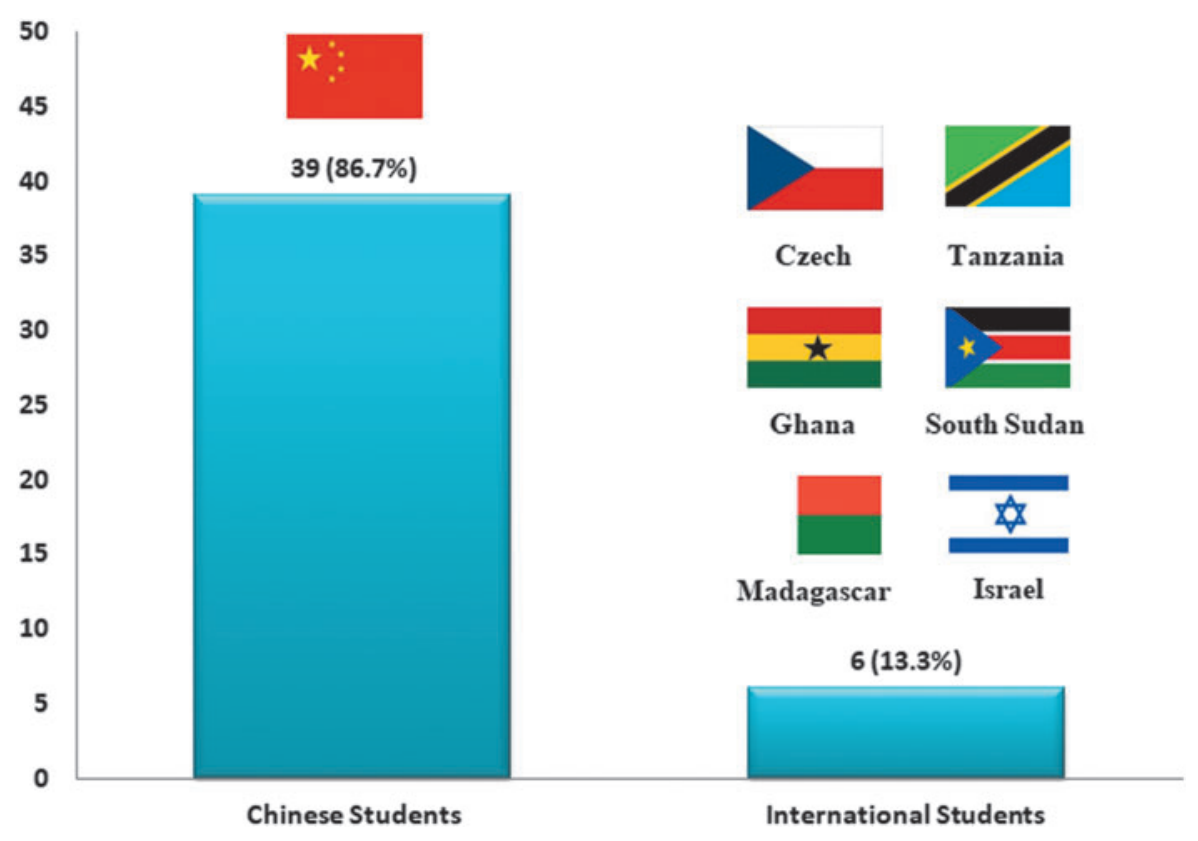


biobanking course to the list of Biobank Education Opportunities on the ISBER website. This activity will strengthen the capacity of national and international cooperation on promoting training future well-prepared biobankers.

\section{Author Disclosure Statement}

No conflicting financial interests exist.

\section{Funding Information}

This study was supported by funding from the National Key Research and Development Program of China (Grant No. 2016YFC1201800), the Key Research and Development Program of Hunan Province, China (Grant No. 2018SK2090), the Hunan Provincial Degree and Graduate Education Reform Research Program (Grant No. 2019JGZD010), and the Research Program on Graduate Education and Teaching Reform at Central South University (Grant No. 2019JG005).

\section{References}

1. Artene S-A, Ciurea ME, Purcaru SO, et al. Biobanking in a constantly developing medical world. Sci World J 2013; 2013:343275.

2. Hofman P, Brechot C, Zatloukal K, Dagher G, Clement B. Public-private relationships in biobanking: A still underestimated key component of open innovation. Virchows Arch Int J Pathol 2014;464:3-9.

3. Gilbert Ahamer D, Macheiner T, Huppertz B, Sargsyan K. Innovative ways for information transfer in biobanking. Campus Wide Inf Syst 2013;30:379-385.

4. Gormally E, Hardy I, Caboux E, et al. Training the next generation of biobankers: A two-year master's course in the management of biobanks. Biopreserv Biobank 2017;15: 438-450.

5. O'Donoghue S, Matzke L, Watson P. ISBER best practicebased education: ISBER-Canadian tissue repository network introduction to biobanking. Biopreserv Biobank 2018; 16:13-15.

6. Abdelhafiz AS, Fouda MA, El-Jaafary SI, et al. Targeting future customers: An introductory biobanking course for undergraduate students of life sciences. Biopreserv Biobank 2017;15:350-359.

7. Matzke EAM, O'Donoghue S, Barnes RO, et al. Certification for biobanks: The program developed by the Canadian Tumour Repository Network (CTRNet). Biopreserv Biobank 2012;10:426-432.

8. Chen H, Chan B, Joly Y. Privacy and biobanking in China: A case of policy in transition. J Law Med Ethics 2015;43: 726-742.

9. Zhang Y, Li Q, Wang X, Zhou X. China Biobanking. Adv Exp Med Biol 2015;864:125-140.

10. Gan R, Wang H, Song Y, Fan J, Xiong Y. Chinese biobanking initiatives. Biopreserv Biobank 2015;13:4-7.

11. Vaught J. Rapid expansion of biobanking in China. Genet Eng Biotechn N 2018;38:20.

12. Li H, Ni M, Wang P, Wang X. A survey of the current situation of clinical biobanks in China. Biopreserv Biobank 2017;15:248-252.

13. Lqbal M. WeChat Revenue and Usage Statistics (2019). www.businessofapps.com/data/wechat-statistics (accessed October 23, 2019).

14. Watson PH, Nussbeck SY, Carter C, et al. A framework for biobank sustainability. Biopreserv Biobank 2014;12:60-68.

15. De Souza YG. Sustainability of biobanks in the future. Adv Exp Med Biol 2015;864:29-35.

16. Zhang Y, Li Q, Wang X, Zhou X. China Biobanking. In: Karimi-Busheri F, ed. Biobanking in the 21st Century. Advances in Experimental Medicine and Biology, Springer, Cham; 2015;864:125-140.

Address correspondence to: Jufang Huang, MD, PhD Department of Anatomy and Neurobiology School of Basic Medical Sciences Central South University

172 Tongzipo Road, Medical Morphology Building Office 503

Changsha 410013

China

E-mail: huangjufang@csu.edu.cn 